\title{
Thalassemia patients with malocclusion
}

\author{
Mohamad Azhar Ibrahim Kharsa* \\ Dental Center, Scientist Fellow of “American Society of Laser Medicine and Surgery”, WFO Fellow, Saudi Arabia
}

\section{Summary}

This case report is to present two cases of young boys with $\beta$ thalassemia, have skeletal class II convex profile, protrusion of the maxilla and mandible, protrusion of the upper incisors and smaller incisor widths. Cephalometric x-ray shows overgrowth of the maxilla bone, with presence of bone voids and hiatuses. The treatment of patients with $\beta$ thalassemia is usually controversy, require good diagnosis, investigations and treatment plan.

\section{Introduction}

Thalassemia is an inherited disorder of hemoglobin $(\mathrm{Hb})$ synthesis, so it is an anemia transmits congenitally. Thalassemia varies from asymptomatic forms to severe or even fatal entities. Thalassemia has names as "Mediterranean anemia", Cooley anemia "Thomas Cooley", or $\beta$ thalassemia. The word thalassemia is a Greek term derived from thalassa, which means "the sea" (referring to the Mediterranean), and emia, which means "related to blood." However, as a simplified identification to Thalassemia: "Cooley's anaemia or $\beta$ thalassemia or mediterranean anaemia is a blood disease characterised by malformation of the skull and long bones, which confers a typical appearance on the patient" $[1,2]$.

The malocclusion "Thalassemia caused" is available to be prevented by "intensive blood transfusion programme or by bone-marrowtransplantation". However, such preventive procedures should be followed for the growing children since the first years of their lives. Unfortunately, the substitution of preventive treatments (since the childhood first years) is the surgery with its sequels and aftermaths.

It has been reported in the literature that the major oral change in thalassaemic patients is enlargement of the maxilla caused by bone marrow expansion. This results in a characteristic appearance known as chipmunk faces. Affected patients usually suffer from spacing of the teeth and forward drift of the maxillary incisors, so that orthodontic treatment may be indicated [3-6]. Although $\beta$ thalassemia major is considered to be a common genetic disorder, there are few up-to-date research reports in the literature with regard to the morphological and dimensional characteristics of the dental arch in affected patients world wide.

\section{Case report}

Two cases of 10-12 year old growing boys from the same family (Figures 1 and 2) present to clinic complaining of protruded maxilla, spacing between teeth and protrusion of the upper incisor teeth. They are affected by $\beta$ thalassemia. Clinical examination showed skeletal Class II ( Convex profile ) (Figures 3 and 4), protrusion of maxilla and mandible, protrusion of upper incisor teeth with smaller widths,

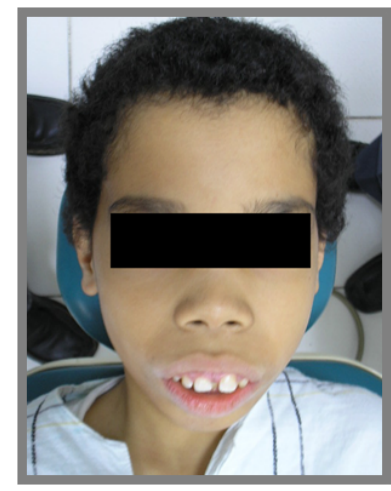

Figure 1. First Case: 10 years old growing child Affected by $\beta$ thalassemia

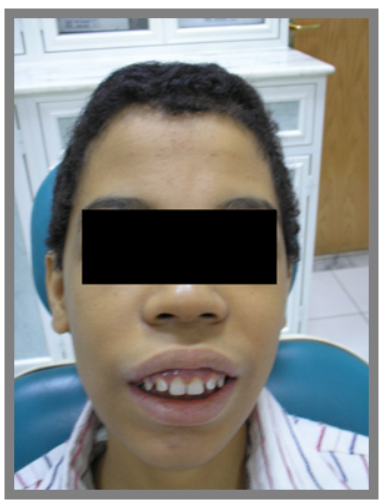

Figure 2. Second Case: 12 years old growing child Affected by $\beta$ thalassemia

increase in maxillary vertical height, incompetent lips, increase in overjet and generalized spacing between teeth.

Lateral Cephalometric radiograph, elicits the protrusion of the maxilla and mandible, because of the effect of the thalassemia aftermaths of "overgrowth" of the maxillas bones. Notice that bone voids and hiatuses are vast consequent to the vast marrow spaces pertinent to this type of thalassemia (Figure 5). Also, Cephalometric radiograph shows the maxillary sinuses where they are clearly extraordinary vast (Figures 6-8).

^Correspondence to: Mohamad Azhar Ibrahim Kharsa, PhD (Ortho), Dental Center, Scientist Fellow of "American Society of Laser Medicine and Surgery", WFO Fellow, Saudi Arabia, E-mail: dr.orth@gmail.com

Key words: thalassemia patient, $\beta$ thalassemia, malocclusion, bone abnormality Received: March 28, 2020; Accepted: May 27, 2020; Published: May 29, 2020 


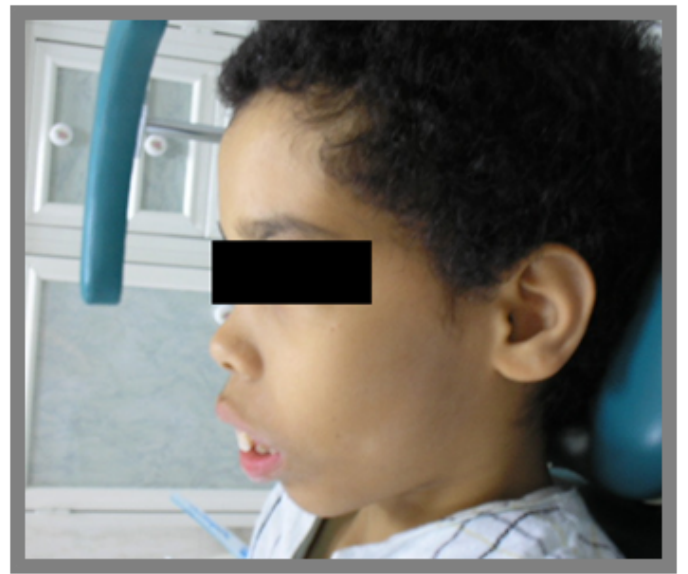

Figure 3. Left lateral side view of the First case

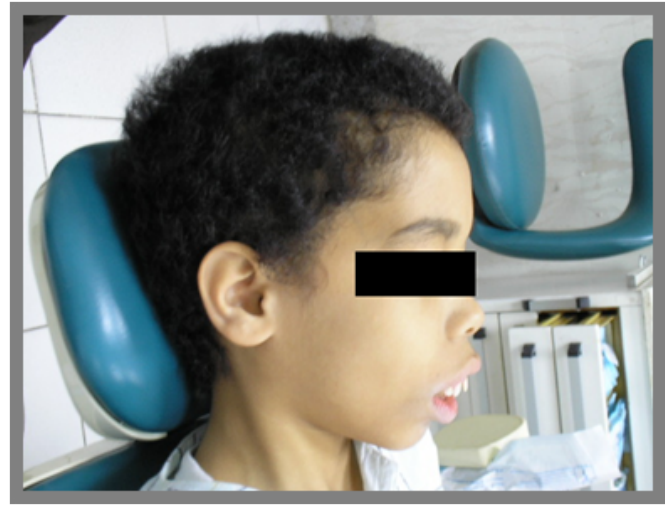

Figure 4. Right lateral side view of the First case

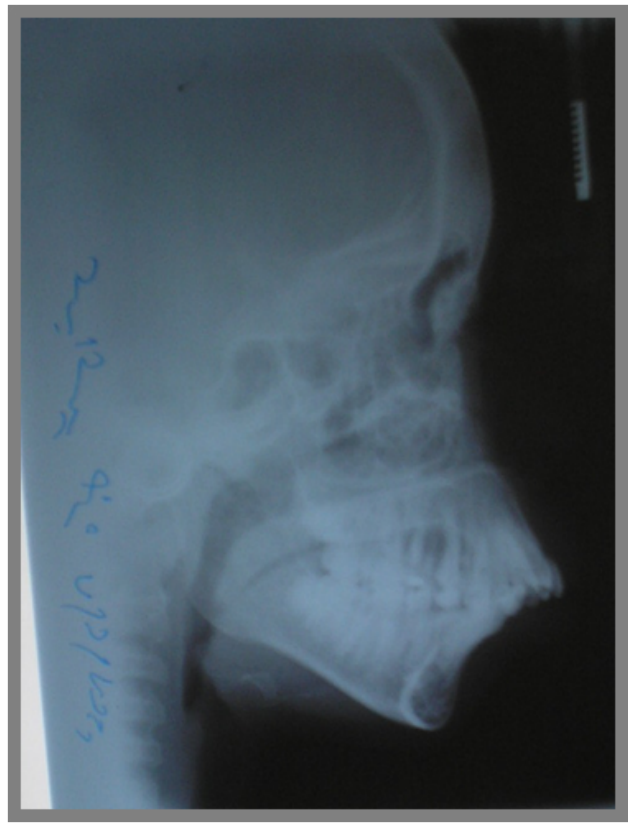

Figure 5. Lateral Cephalometric of the First patient

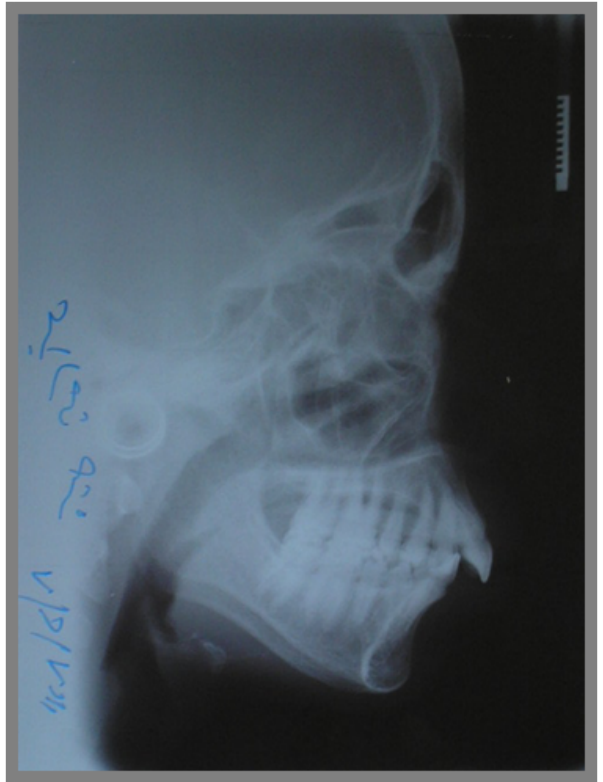

Figure 6. Lateral Cephalometric of the Second patient

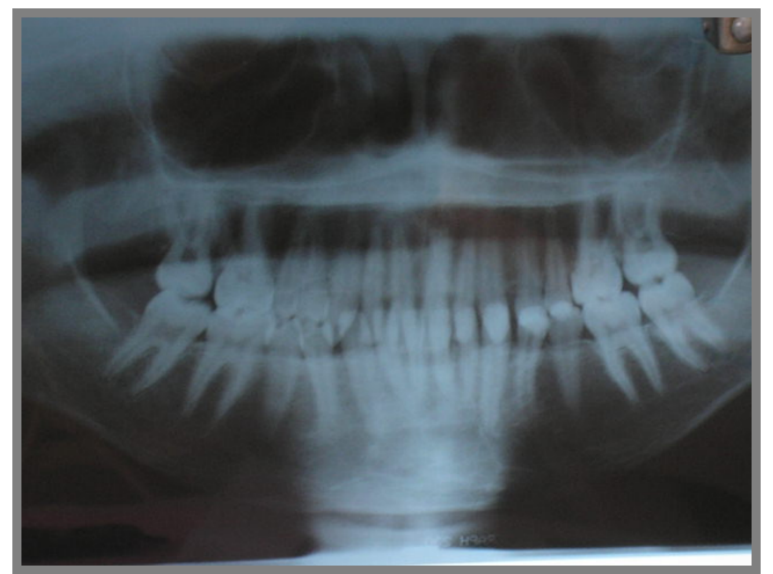

Figure 7. OPG Radiograph of the First patient

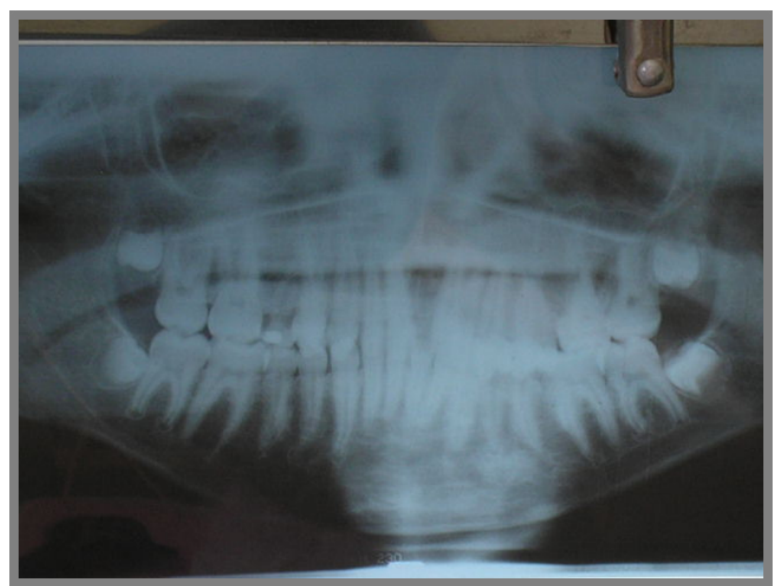

Figure 8. OPG Radiograph of the Second patient 


\section{Discussion}

Literatures about the thalassemia and orthodontic treatment, Cephalometric characteristics and best managements to thalassemic patients orthodontically are rare in general. It has been reported in the literature that the major oral change in thalassaemic patients is enlargement of the maxilla caused by bone marrow expansion. Patients suffering $\beta$ thalassemia show great clinical variability in the systemic signs and symptoms with which they present. Because of the severe anemia they suffer in early childhood, bony changes, retardation in growth, splenomegaly, and iron overload and consequent deposition in tissues all occur.

\section{Conclusion}

Patients affected with thalassemia, will have bone abnormalities such as overgrowth of the maxilla and the mandible. chipmunk faces is one of the most common signs of thalassemic patients because of the protrusion of maxilla and mandible, also protrusion of incisor teeth. Orthodontist treating of this condition need to be aware of the importance of good diagnosis, investigations and treatment plan.

\section{References}

1. Weatherall DJ, Clegg JB (1981) The b thalassaemia. In: The thalassaemia syndromes. Oxford: Blackwell Science 149-56.

2. Duggal MS, Bedi R, Kinsey SE, Williams SA (1996) The dental management of children with sickle cell disease and $\beta$ - thalassaemia: a review. International Journal of Paediatric Dentistry 6: 227-234.

3. Scully C, Cawson RA (1993) Medical Problems in Dentistry, 3rd edn. Oxford: Wright.

4. Merz ML, Isaacson RJ, Germane N, Rubenstein LK (1991) Tooth diameters and arch perimeters in a black and a white population. American Journal of Orthodontics and Dentofacial Orthopedics 100: 53-58.

5. Bassimitci S, Yucel-Eroglu E, Akalar M (1996) Effects of thalassemia major on components of the craniofacial complex. British Journal of Orthodontics 23: 157-162.

6. Kaplan RI, Werther R, Castano FA (1964) Dental and oral findings in Cooley's anemia: a study of fifty cases. Annals of the New York Academy of Sciences 119: 664-666.

Copyright: $(2020$ Kharsa MAI. This is an open-access article distributed under the terms of the Creative Commons Attribution License, which permits unrestricted use, distribution, and reproduction in any medium, provided the original author and source are credited. 